\title{
Differences in duration discrimination of filled and empty auditory intervals as a function of base duration
}

\author{
THOMAS H. RAMMSAYER \\ University of Bern, Bern, Switzerland
}

\begin{abstract}
In the present experiments, participants were presented with two time intervals that were marked by auditory signals, and their task was to decide which of the two was longer in duration. In Experiment 1, the base durations were 50 and 1,000 msec, whereas in Experiment 2, seven different base durations ranging from 50 to 1,000 msec were employed. It was found that filled intervals (continuous tones) were discriminated more accurately than empty intervals (with onset and offset marked by clicks) at the $50-\mathrm{msec}$ base duration, whereas no performance differences could be shown for longer ones. The findings are consistent with the notion of a unitary timing mechanism that governs the timing of both filled and empty auditory intervals, independent of base durations. A likely conceptual framework that could explain better performance with filled as compared with empty intervals represents an information-processing model of interval timing that evolved from scalar timing theory. According to this account, a performance decrement observed with empty intervals may be due to a misassignment of pulses generated by an internal pacemaker.
\end{abstract}

In psychophysical studies on duration discrimination, basically two types of intervals are used (cf. Woodrow, 1951). One type is the filled interval, and the other type is the empty interval. In filled intervals, a signal is presented continuously throughout the interval, whereas in empty intervals, only the onset and the offset of the interval are marked by a brief sensory event. Thus, an empty interval is a silent duration with no signal present during the interval itself. In the literature, a highly puzzling picture of rather inconsistent findings arises with regard to the question of how the type of interval affects performance on duration discrimination. As will be discussed in more detail below, some studies found better performance on duration discrimination with filled than with empty intervals, whereas other studies reported the opposite effect or failed to reveal any differences at all. Because of the large number of highly ambiguous results, in his comprehensive reviews of the influence of filled and empty intervals on performance on duration discrimination in humans, Grondin $(2001,2003)$ arrived at the conclusion that, to date, no definitive statement on this issue can be made. Most interestingly, similarly inconclusive results have been reported from animal studies (e.g., Kraemer, Randall, \& Brown, 1997; MacInnis, 2007; Miki \& Santi, 2005; Santi, Keough, Gagne, \& van Rooyen, 2007; Santi, Miki, Hornyak, \& Eidse, 2006). At this point, it seems that differences in duration discrimination with filled and empty intervals may depend on various factors, such as the duration of the intervals to be compared, the sensory modality in which the intervals are presented, the physical characteristics of the markers defining the empty intervals, or the psychophysical procedure applied (cf. Allan, 1979; Fraisse, 1978; Grondin, 2001, 2003, 2008).

Another question at issue when comparing performance on duration discrimination with filled and empty intervals refers to the definition of the duration of an empty interval. When comparing filled and empty intervals, the researcher is faced with the problem of appropriately equating the physical duration of both types of intervals. In the case of a filled interval, the physical duration is directly reflected by the presentation time of the sensory signal. There is some disagreement, however, with regard to empty intervals. On the basis of the outcome of his studies on the perceived duration of empty auditory intervals in the subsecond range, Woodrow (1928) concluded that "It is entirely impossible to listen to the interval without also paying some attention to the limiting sounds. One's reaction is to some extent always a reaction to the temporal form as a whole" (p. 192). More recently, Grondin, Ivry, Franz, Perreault, and Metthé (1996) also reported longer perceived duration with empty intervals in the subsecond range marked by a $100-\mathrm{msec}$ onset and a 5-msec offset marker, as compared with empty intervals bounded by 5 -msec onset and offset markers. This longer perceived duration with the longer onset marker could be observed even though participants were instructed to judge the duration between the offset of the first marker and the onset of the second marker. These findings of an influence of onset-marker duration on perceived duration suggest that the internal representation of an empty inter-

T. H. Rammsayer, thomas.rammsayer@psy.unibe.ch 
val may be governed by the interonset interval rather than by the offset-to-onset duration of the two markers.

Unlike perceived duration, however, in Grondin et al.'s (1996) study, performance on duration discrimination appears to be largely unaffected by marker duration. Experiments by Rammsayer and Leutner (1996) also failed to demonstrate dependence of temporal discrimination performance on marker durations ranging from 3 to $175 \mathrm{msec}$. More specifically, discrimination performance was virtually identical, regardless of whether the empty intervals to be compared were bounded by 3 - or $150-\mathrm{msec}$ markers. This outcome is consistent with the notion that timing of empty intervals is based on the offset-to-onset duration of the two markers. More direct evidence for the offset-onset hypothesis has been provided by an eventrelated potential study applying a duration-mismatch negativity $(\mathrm{MMN})$ paradigm to investigate the temporal processing of empty auditory intervals (Tse \& Penney, 2006). With this approach, electrophysiological measures of preattentive deviance detection were obtained as a function of onset-marker duration and the interval between the marker stimuli. Analyses of MMN difference waveforms clearly indicated that empty intervals are timed from the offset of the first marker to the onset of the second marker rather than from onset to onset of the first and second marker, respectively.

The experimental verification of the offset-onset hypothesis by Tse and Penney (2006) represents a most crucial point for the study of differences in temporal discriminability of filled and empty intervals. Given the validity of the offset-onset hypothesis, for an empty interval corresponding to, for example, a 600-msec filled interval, the time between the offset of the first marker and onset of the second marker should be $600 \mathrm{msec}$. Nevertheless, for some researchers (e.g., Pfeuty, Ragot, \& Pouthas, 2008), implicitly proceeding from the questionable notion that the duration of an empty interval is represented by the time from the onset of the first marker until the onset of the second marker, the duration of the first marker is contained in the 600-msec empty interval. If, as in the case of Pfeuty et al., for instance, the first marker has a duration of $50 \mathrm{msec}$, the time between the first and the second marker would be set to $550 \mathrm{msec}$. If the discriminabilty of filled and empty intervals is compared under this latter condition, better performance with empty than with filled intervals would be the expected outcome. This is because, according to Weber's law, the change in stimulus magnitude that will be just noticeable is a constant ratio of the standard stimulus (here, standard duration); thus, it must be larger with the filled 600-msec interval than with the empty 550-msec interval for reaching comparable levels of discrimination (cf. Grondin, 1993). Hence, for a direct comparison of performance on duration discrimination with filled and empty intervals, studies should be considered only if the standard duration of the filled interval corresponds exactly to the time between the offset of the first marker and the onset of the second marker bounding the respective empty interval. For instance, when directly comparing the discriminability of a $600-\mathrm{msec}$ filled interval with a corresponding empty interval, the latter one should be defined by an offset-to-onset duration of $600 \mathrm{msec}$.

The present study was designed to systematically assess potential differences in performance on auditory duration discrimination as a function of the type of interval (filled vs. empty) and base duration. Base duration refers to the (range of) standard durations used in studies on the discriminability of filled and empty intervals. Base durations are commonly on the order of tens to hundreds of milliseconds (Penney, 2003). In the present study, therefore, base durations ranging from 50 to $1,000 \mathrm{msec}$ were employed.

There is converging evidence for the notion that the psychophysical task applied for quantification of temporal discrimination performance may influence the results. Lapid, Ulrich, and Rammsayer (2008, 2009a) compared the estimates of the difference limen (DL) from two of the most common tasks in psychophysics: the two-alternative forced choice (2AFC) and the reminder tasks. In the reminder task, the standard is always presented first and is followed by the comparison, whereas the standard and the comparison are presented in random order across trials in 2AFC tasks. In both tasks, participants have to indicate whether the first or second interval appeared longer. As a supplementary aim, Lapid et al. (2008) combined the two tasks with both adaptive and nonadaptive procedures for threshold estimation. The results indicate that although there is no effect of the procedure in which data were obtained on DL estimates, a discrepancy existed between the two tasks. A 2 AFC task yielded DL estimates almost twice as high as those of the reminder task. This discrepancy may account for some of the inconsistent findings when comparing performance on duration discrimination with filled and empty intervals across different studies. Also, Grondin (1993) was confronted with inconsistent results as a function of the psychophysical task that was applied. For example, when comparing the effect of filled and empty auditory intervals with a base duration of $250 \mathrm{msec}$ by means of the single-stimulus method (Grondin, 1993, Experiment 1), he observed better discrimination for empty than for filled intervals. No such performance difference could be revealed with an adaptive 2 AFC task (Grondin, 1993, Experiment 4). Because the very nature of the influence of the psychophysical task on discrimination performance remains largely unknown to date (see Lapid et al., 2008), an identical psychophysical task was employed in the two present experiments.

In Experiment 1 of the present study, better discrimination performance with filled than with empty intervals for a $50-\mathrm{msec}$ base duration could be established, whereas virtually no difference between filled and empty was observed for a 1-sec base duration. The major goal of Experiment 2, therefore, was to identify the critical base duration at which a reliable difference in discriminability between filled and empty auditory intervals occurs for the first time. The first systematic investigation of the variation of difference thresholds with duration for both filled and empty intervals was performed by Grondin (1993, Experiment 5). In the present Experiment 2, we complemented and expanded Grondin's (1993) research in several ways. Whereas the shortest base dura- 
tion investigated by Grondin (1993) was $125 \mathrm{msec}$, base durations as short as $50 \mathrm{msec}$ were employed in Experiment 2. Furthermore, in Grondin's (1993, Experiment 5) pioneering research, data were obtained from only 4 subjects; for 3 subjects, difference thresholds were estimated with the many-to-few-method; for 1 subject, difference thresholds were estimated with an adaptive 2AFC task. In contrast, in the present study, a much larger sample was tested with an identical psychophysical procedure. Doing this should both facilitate the use of inferential statistical techniques for data analysis and control for a possible confound produced by different psychophysical timing tasks. Eventually, Grondin (1993) applied an experimental design with type of interval (filled and empty) as two levels of a within-subjects factor. In the present Experiment 2, however, a between-subjects design was used to avoid potential transfer effects from one type of interval to another, due to perceptual learning (cf. Karmarkar \& Buonomano, 2003; Lapid, Ulrich, \& Rammsayer, 2009b). Such a systematic comparison of the discriminability of filled and empty intervals is expected to contribute to a better understanding of the mechanisms involved in the processing of temporal information (Allan, 1979).

\section{EXPERIMENT 1}

In an early attempt to identify differences in duration discrimination with filled and empty intervals, Fraisse (1978) contrasted results from two studies using auditory filled (Small \& Campbell, 1962; Stott, 1933) and empty (Getty, 1975; Woodrow, 1930) intervals. This comparison suggested better performance for empty than for filled intervals. Furthermore, Weber fractions stayed nearly constant for base durations ranging from 400 to $2,000 \mathrm{msec}$, but increased substantially with shorter base durations. Two studies by Abel (1972a, 1972b) - one with empty and one with filled auditory intervals - revealed performance with filled intervals ranging from 10 to $960 \mathrm{msec}$ to be more accurate than performance with empty intervals. In both studies, the method of constant stimuli-a forced choice procedure with fixed standard - was employed. It should be noted, however, that this comparison was not the focus of Abel's studies.

The conclusion of better discrimination with filled than with empty auditory intervals, drawn from Abel's (1972a, 1972b) data, has been confirmed by Rammsayer and his colleagues (Rammsayer, 1994b; Rammsayer \& Altenmüller, 2006; Rammsayer \& Brandler, 2004; Rammsayer \& Lima, 1991), at least for very brief intervals in the range of milliseconds. In these studies, discriminations of filled and empty auditory intervals with a base duration of $50 \mathrm{msec}$ were directly compared with each other by means of a within-subjects design. This performance advantage observed with filled intervals was corroborated by a study using a between-subjects design (Rammsayer, 1994a). In all of these experiments, adaptive forced choice procedures with a fixed standard (= base duration) was used.

Unlike Rammsayer and colleagues, Grondin (1993) failed to find a reliable performance difference between filled and empty auditory intervals either with the method of single stimulus (Experiment 2: Mean percentages of correct responses were 78.3 and 76.2 for filled and empty intervals, respectively) or with an adaptive forced choice procedure (Experiment 4: Mean difference thresholds were 11.3 and $10.6 \mathrm{msec}$ for filled and empty intervals, respectively) for a 50-msec base duration. Additional data that were obtained with adaptive forced choice procedures also yielded no reliable differences in discrimination performance between filled and empty auditory intervals for a 250-msec base duration (Grondin, 1993, Experiment 4: Mean difference thresholds were 33.1 and $35.7 \mathrm{msec}$ for filled and empty intervals, respectively) as well as for base durations of 400 and $800 \mathrm{msec}$ (Grondin, Meilleur-Wells, Ouellette, \& Macar, 1998, Experiment 1: Mean difference thresholds were 38.7 and $45.7 \mathrm{msec}$ for filled and empty 400-msec intervals, respectively, and 80.1 and $80.0 \mathrm{msec}$ for filled and empty 800 -msec intervals, respectively). It should be noted, however, that superior discrimination performance was found for empty, as opposed to filled, auditory intervals using the method of single stimuli (Grondin, 1993, Experiments 1 and 3: Mean percentages of correct responses across both experiments were 67.9 and 76.3 for filled and empty intervals, respectively) or a forced choice procedure with a base duration of $250 \mathrm{msec}$ (Grondin, 1993, Experiment 3: Mean percentages of correct responses were 71.9 and 75.4 for filled and empty intervals, respectively).

A tentative interpretation of the available data gives rise to the notion of superior discrimination performance with filled as compared with empty auditory intervals at extremely brief base durations in the range of milliseconds - at least when applying an adaptive forced choice procedure. This performance advantage, however, is expected to vanish with increasing base durations. The goal of Experiment 1, therefore, was to directly establish the direction and the degree of performance differences in duration discrimination of filled and empty auditory intervals in the range of tens of milliseconds as well as in the 1 -sec range by means of a within-subjects design.

\section{Method}

Participants. The participants were 38 male and 38 female adult volunteers (mean age, $22.7 \pm 2.5$ years). All of the participants were undergraduate psychology students and received course credits for taking part in this experiment. They had normal hearing and were naive about the purpose of the experiment.

Apparatus and Stimuli. The presentation of the intervals to be judged and the recording of participants' responses were controlled by a computer. Filled intervals consisted of white noise from a computer-controlled sound generator (Phylab Model 1) that was presented binaurally through headphones (Vivanco SR85). The empty intervals were marked by onset and offset white-noise bursts that were $3 \mathrm{msec}$ in duration. Filled and empty intervals were presented with an intensity of 66 and $88 \mathrm{~dB}$, respectively. These different levels of intensity were chosen to achieve equal loudness in the two conditions on the basis of the results of a prior pilot experiment in which 12 participants were asked to adjust the loudness of a 3-msec click until it matched that of a 50-msec tone.

Procedure. Two independent variables-type of interval (filled and empty) and range of base duration (50 and 1,000 msec) —were factorially combined in a within-subjects design to yield four experimental conditions. Thus, the duration discrimination task consisted of four blocks, with each block representing one experimental con- 
dition. The order of blocks was counterbalanced across participants. Each block consisted of 64 trials, and each trial consisted of one standard interval (= base duration) and one comparison interval. The duration of the comparison interval varied according to an adaptive rule (Kaernbach, 1991) to estimate $x_{.25}$ and $x_{.75}$ of the individual psychometric function - that is, the two comparison intervals at which the response "longer" was given with a probability of .25 and .75 , respectively.

For duration discrimination of brief stimuli in the range of milliseconds, the standard interval was $50 \mathrm{msec}$, and the initial durations of the comparison interval were $15 \mathrm{msec}$ below and above the standard interval for $\mathrm{x}_{25}$ and $\mathrm{x}_{75}$, respectively. To increase efficiency of the adaptive procedure, a larger step size was applied for the initial Trials 1-6 than for Trials 7-32 (cf. Levitt, 1971). Thus, to estimate $\mathrm{x}_{.25}$, the duration of the comparison interval was increased for Trials $1-6$ by $3 \mathrm{msec}$ if the participant had judged the standard interval to be longer and decreased by 9 msec after a "short" judgment. For Trials 7-32, the duration of the comparison interval was increased by $2 \mathrm{msec}$ and decreased by $6 \mathrm{msec}$. The opposite step sizes were employed for $\mathrm{x}_{.75}$.

For temporal discrimination of longer durations, the standard interval was $1,000 \mathrm{msec}$, and the initial values of the comparison interval were 500 and $1,500 \mathrm{msec}$ for $\mathrm{x}_{.25}$ and $\mathrm{x}_{.75}$, respectively. To estimate $\mathrm{x}_{.25}$, the duration of the comparison interval was increased by $100 \mathrm{msec}$ if the participant had judged the standard interval to be longer, and it decreased by $300 \mathrm{msec}$ after a "short" response. For Trials 7-32, the duration of the comparison interval was increased by $25 \mathrm{msec}$ and decreased by $75 \mathrm{msec}$. Again, the opposite step sizes were employed for $\mathrm{x}_{75}$.

In each experimental block, one series of 32 trials converging to $\mathrm{x}_{.25}$ and one series of 32 trials converging to $\mathrm{x}_{.75}$ were presented. Trials from both series were randomly interleaved within a block. The participants were not informed that there was a constant standard interval in every trial.

Each participant was seated at a table with a keyboard and a computer monitor. To initiate a trial, the participant pressed the space bar; an auditory presentation began $900 \mathrm{msec}$ later. The two intervals were presented with an interstimulus interval of $900 \mathrm{msec}$. The participant's task was to decide which of the two intervals was longer and to indicate his or her decision by pressing one of two designated keys on a computer keyboard. One key was labeled "First interval longer," and the other was labeled "Second interval longer." The instructions to the participants emphasized accuracy; there was no requirement to respond quickly. After each response, visual feedback ("+," i.e., correct; "-," i.e., false) was displayed on the computer screen. The next trial started $900 \mathrm{msec}$ after the feedback.

As a measure of performance, mean differences between standard and comparison intervals were computed for the last 20 trials of each series. Thus, estimates of the $25 \%$ - and $75 \%$-difference thresholds in relation to the respective standard intervals were obtained. In a second step, half of the interquartile range [( $75 \%$-threshold value $25 \%$-threshold value) $/ 2$ ], representing the DL (Luce \& Galanter, 1963), was determined for both duration discrimination tasks. With this psychophysical measure, better performance on duration discrimination is indicated by smaller values. For quantification of timing accuracy as a function of base duration, the Weber fraction (DL/ standard duration) was computed for each experimental condition (cf. Killeen \& Weiss, 1987). Thus, Weber fractions can be considered an indicator of relative temporal sensitivity.

\section{Results and Discussion}

With the 50-msec base duration, mean Weber fractions ( \pm standard deviation) were $0.15 \pm 0.053$ and $0.33 \pm 0.147$ for filled and empty intervals, respectively, whereas with the 1,000-msec base duration, almost identical Weber fractions of $0.12 \pm 0.062$ and $0.13 \pm 0.070$ were observed for both types of intervals. A two-way ANOVA with type of interval (filled and empty) and base duration (50 msec and
$1,000 \mathrm{msec}$ ) as within-subjects factors yielded a statistically significant main effect of type of interval $[F(1,75)=$ $\left.104.79, p<.001, \eta^{2}=.583\right]$. The average Weber fraction was $0.13 \pm 0.044$ for filled and $0.23 \pm 0.096$ for empty intervals. Also, the base duration produced a significant main effect $\left[F(1,75)=139.60, p<.001, \eta^{2}=.651\right]$; relative temporal sensitivity was better with the long than with the short base duration, as indicated by Weber fractions of $0.24 \pm 0.091$ and $0.13 \pm 0.052$ for the 50 - and 1,000msec standard intervals, respectively. Theoretically most important, however, the effect of type of interval significantly varied with base duration $[F(1,75)=120.49, p<$ $\left..001, \eta^{2}=.616\right]$. More specifically, a significant effect of type of interval was obtained for the $50-\mathrm{msec}$ base duration [0.15 vs. $0.33, t(75)=-12.54, p<.001]$, but not for the $1,000-$ msec base duration $[0.12$ vs. $0.13, t(75)=$ $-1.18, p=.24]$.

The finding that, for extremely brief auditory intervals in the range of milliseconds, temporal sensitivity is better with filled than with empty intervals is consistent with the outcome of previous studies (Rammsayer, 1994a, 1994b; Rammsayer \& Altenmüller, 2006; Rammsayer \& Brandler, 2004; Rammsayer \& Lima, 1991; Rammsayer \& Skrandies, 1998). The latter studies also reported superior discrimination performance with filled than with empty auditory intervals for base durations ranging from 50 to $100 \mathrm{msec}$. The failure to demonstrate a similar effect of type of interval for the 1,000-msec base duration suggests that differences in temporal processing between filled and empty intervals may become evident only with extremely brief base durations. The absence of a filledempty difference for longer auditory intervals with base durations ranging from 250 to $800 \mathrm{msec}$ has also been reported by Grondin (1993, Experiment 4; Grondin et al., 1998, Experiment 1). As in the present experiment, in these latter studies, an adaptive psychophysical procedure was employed.

\section{EXPERIMENT 2}

The outcome of Experiment 1 indicates that, at base durations as short as $50 \mathrm{msec}$, performance on auditory duration discrimination is markedly better with filled than with empty intervals, whereas for a 1-sec base duration, no such performance difference seems to exist. Therefore, an additional experiment was designed to answer the question of how temporal sensitivity of filled and empty intervals varies with base duration. More specifically, the major focus of Experiment 2 was on identifying the critical base duration at which a reliable difference in discriminability between filled and empty auditory intervals can be observed for the first time.

For this purpose, performance on duration discrimination with filled and empty intervals was assessed for seven different levels of base duration ranging from 50 to $1,000 \mathrm{msec}$. Base durations accordingly were set at 50 , $100,200,400,600,800$, and 1,000 msec. In addition, unlike in Experiment 1, type of interval was designed as a between-subjects factor in Experiment 2. Thus, in Experiment 2, we aimed at expanding the outcome of Experi- 
Table 1

Initial Values of the Comparison Interval for the $x_{.25}$ and $\mathrm{x}_{.75}$ Series and Stepsizes $\Delta_{-}$and $\Delta_{+}$for the $x_{.75}$ Series As a Function of Standard Duration

\begin{tabular}{|c|c|c|c|c|c|c|}
\hline \multirow{3}{*}{$\begin{array}{c}\text { Base } \\
\text { Duration }\end{array}$} & \multicolumn{2}{|c|}{$\begin{array}{c}\text { Initial Value } \\
\text { of Comparison }\end{array}$} & \multicolumn{2}{|c|}{ Stepsize $\Delta_{-}$} & \multicolumn{2}{|c|}{ Stepsize $\Delta_{+}$} \\
\hline & $\mathrm{X}_{.25}$ & $\mathrm{X}_{.75}$ & Trials & Trials & Trials & Trials \\
\hline & Series & Series & $1-6$ & $7-32$ & $1-6$ & $7-32$ \\
\hline 50 & 35 & 65 & 3 & 2 & 9 & 6 \\
\hline 100 & 65 & 135 & 5 & 3 & 15 & 9 \\
\hline 200 & 130 & 270 & 9 & 6 & 27 & 18 \\
\hline 400 & 300 & 500 & 15 & 10 & 45 & 30 \\
\hline 600 & 440 & 760 & 25 & 17 & 75 & 51 \\
\hline 800 & 500 & 1,100 & 70 & 22 & 210 & 66 \\
\hline 1,000 & 500 & 1,500 & 100 & 25 & 300 & 75 \\
\hline
\end{tabular}

Note-All of the data are in milliseconds.

ment 1 in two respects: first, by examining the influence of base duration on the discriminability of filled and empty intervals in more detail and, second, by testing the validity of the results of Experiment 1 on the basis of a between-subjects design. A major reason for employing a between-subjects design was to avoid transfer effects from one type of interval to the other due to perceptual learning. In a recent study, Lapid et al. (2009b) provided experimental evidence for temporal perceptual learning. After training with empty auditory intervals with a base duration of $100 \mathrm{msec}$, participants significantly improved their discrimination performance in an untrained filled-interval condition with the same base duration. Similar effects were reported by Karmarkar and Buonomano (2003).

\section{Method}

Participants. A new group of 48 volunteers (46 males and 2 females; mean age, $22.2 \pm 4.1$ years) participated in Experiment 2. They were randomly assigned to either a filled- or an empty-interval condition with the restriction that they were evenly distributed across the two experimental conditions. All had normal hearing and were naive about the purpose of the study.

Apparatus, Stimuli, and Design. The apparatus and stimuli were the same as in Experiment 1. The experimental design was similar to that of Experiment 1 except that the type of interval (filled and empty) was designed as a between-subjects factor, whereas base duration represented a within-subjects factor comprising seven factor levels (50-, 100-, 200-, 400-, 600-, 800-, and 1,000-msec standard intervals).

Procedure. All trials of a given standard interval were presented blockwise; that is, the duration of the standard interval was kept constant across the trials within a single block. The order of blocks was counterbalanced across participants. As in Experiment 1, each block consisted of 64 trials, and each trial consisted of one standard interval (= base duration) and one comparison interval. The same adaptive rule as in the previous experiment was applied to estimate $\mathrm{x}_{.25}$ and $\mathrm{x}_{.75}$ of the individual psychometric function.

To estimate $\mathrm{x}_{.75}$, the duration of the comparison interval was increased by $\Delta_{+}$msec if the participant had judged the comparison interval to be shorter, and it decreased by $\Delta_{-}$after a "long" judgment. The opposite step sizes were employed for $\mathrm{x}_{.25}$. Because absolute precision of timing depends on the standard duration, the step sizes $\Delta_{+}$and $\Delta_{-}$were adjusted for each base duration. Step sizes as well as the initial value of the comparison intervals for each base duration were chosen on the basis of the results of a prior pilot experiment and are given in Table 1.

\section{Results and Discussion}

Figure 1 depicts Weber fractions for filled and empty intervals as a function of base duration. A two-way ANOVA with the factors type of interval and base duration was performed for Weber fractions. Weber fractions significantly differed as a function of base duration $[F(6,276)=46.66$, $\left.p<.001, \eta^{2}=.504\right]$. There also was a reliable main effect of type of interval $\left[F(1,46)=5.22, p=.03, \eta^{2}=\right.$ $.102]$, indicating better discrimination performance with filled than with empty intervals; mean Weber fractions

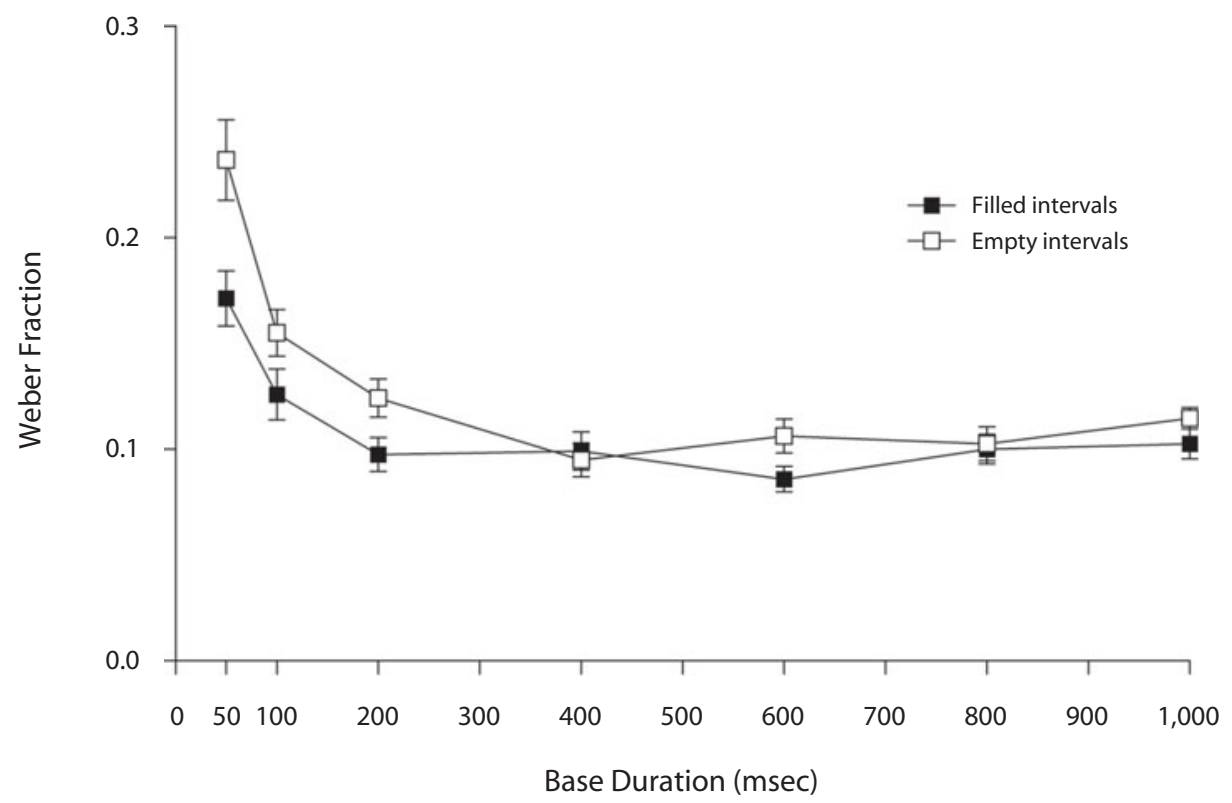

Figure 1. Relative temporal sensitivity as indicated by mean Weber fractions $( \pm S E M)$ for filled and empty intervals as a function of base duration. 
were $0.11 \pm 0.030$ and $0.13 \pm 0.034$ for filled and empty intervals, respectively.

Most importantly, however, as in Experiment 1, the interaction between type of interval and base duration was highly significant $\left[F(6,276)=4.03, p=.001, \eta^{2}=.081\right]$. There was a numerically larger effect of type of interval on Weber fractions when participants discriminated short auditory intervals not exceeding $200 \mathrm{msec}$ as compared with longer ones (see Figure 1). More specifically, post hoc Tukey's HSD tests (see Kirk, 1995) revealed a reliably better relative temporal sensitivity with filled than with empty intervals for the 50 -msec base duration $(p<.001)$; mean Weber fractions were $0.17 \pm 0.062$ and $0.24 \pm 0.094$ for the filled and empty intervals, respectively. For longer base durations, this difference gradually disappeared and no longer became significant.

To assess the interaction of type of interval and base duration more thoroughly, two separate one-way ANOVAs with the repeated measures factor base duration were conducted. One ANOVA included only Weber fractions for filled intervals, and a second one included only those for the empty intervals. For filled intervals $[F(6,138)=16.51$, $\left.p<.001, \eta^{2}=.318\right]$, this additional analysis showed reliably reduced relative temporal sensitivity, as indicated by a higher Weber fraction, for the $50-\mathrm{msec}$ base duration as compared with all other base durations (Tukey's HSD test: $p<.001$ for all comparisons). No such difference was yielded for longer base durations.

A similar pattern of results could be established for duration discrimination of empty intervals $[F(6,138)=$ $\left.30.84, p<.001, \eta^{2}=.573\right]$. The Weber fraction for the 50 -msec base duration was markedly higher than those of all the other base durations (Tukey's HSD test: $p<.001$ for all comparisons). A higher Weber fraction, indicating lower relative temporal sensitivity, was observed also for the 100-msec base duration as compared with the base durations longer than $200 \mathrm{msec}$ ( $p<.05$ for all comparisons). No significant differences in Weber fractions were found among base durations ranging from 200 to $1,000 \mathrm{msec}$. This finding suggests that, with empty auditory intervals, a deteriorating effect of base duration on relative temporal sensitivity is also limited to brief base durations not exceeding $100 \mathrm{msec}$.

Taken together, the most intriguing finding of Experiment 2 was that differences in temporal discriminability between filled and empty auditory intervals seem to be limited to intervals shorter than $100 \mathrm{msec}$. For such extremely brief intervals, performance on duration discrimination was reliably better with filled than with empty intervals.

\section{GENERAL DISCUSSION}

The goal of Experiment 1 was to directly establish the direction and the degree of performance differences in duration discrimination of filled and empty auditory intervals in the range of tens of milliseconds, as well as in the 1 -sec range, by means of a within-subjects design. This experiment revealed significantly better discrimination performance with filled than with empty intervals for a 50-msec base duration, whereas virtually no difference between filled and empty was observed for the 1-sec base duration. Experiment 2 was designed to replicate and to expand these findings by identifying the critical range of base durations in which differences in the discrimination of filled and empty auditory intervals begin to become apparent. For this purpose, seven levels of base duration were employed, ranging from 50 to $1,000 \mathrm{msec}$. Again, findings indicated better performance on duration discrimination with filled than with empty intervals at a base duration of $50 \mathrm{msec}$. No difference in the discriminability of filled and empty intervals could be shown for longer base durations ranging from 100 to $1,000 \mathrm{msec}$.

This latter finding is consistent with experimental data reported by Grondin (1993, Experiment 4) for 250-msec base durations as well as for 400- and 800-msec base durations (Grondin et al., 1998, Experiment 1). In addition, a study by Fitzgibbons and Gordon-Salant (1994), using a base duration of $250 \mathrm{msec}$ and an adaptive psychophysical procedure, also failed to demonstrate a difference in the discriminability of filled and empty auditory intervals. On the other hand, it should be noted that other studies that did not apply an adaptive psychophysical procedure yielded contradictory results. Abel's (1972a, 1972b) data suggested superior performance on duration discrimination with filled than with empty intervals for base durations ranging from 10 to $960 \mathrm{msec}$, whereas Grondin (1993, Experiments 1 and 3) observed better performance with empty, as opposed to filled, auditory intervals at a base duration of $250 \mathrm{msec}$. To date, it remains unclear to what extent these ambiguous results can be accounted for by the different psychophysical procedures applied in those studies.

In the present study, for both types of intervals, significantly higher Weber fractions were observed at extremely brief base durations. For filled intervals, Weber fractions were markedly higher at the $50-\mathrm{msec}$ base duration than at longer ones. A similar difference in Weber fractions could be revealed for empty intervals at base durations of 50 and $100 \mathrm{msec}$ as compared with longer ones. These findings can be accounted for by the generalized form of Weber's law (see Killeen \& Weiss, 1987; Rammsayer \& Grondin, 2000). Within the framework of duration discrimination, Weber's law states that the just noticeable difference in duration (i.e., the difference threshold) increases monotonically as a function of base duration. The generalized form of Weber's law, however, assumes a constant sensory noise that interferes with the genuine timing process. Thus, the constant sensory noise represents a duration-independent source of timing variability whose influence wears off with increasing base duration. At very brief base durations, however, this noise component effectively boosts total timing variance and thus results in higher Weber fractions. In his pioneering study, Getty (1975) provided experimental evidence for the validity of the generalized form of Weber's law for temporal discrimination of empty auditory intervals. He demonstrated that Weber's law, in its strict form, holds for the discrimination of durations ranging from 200 to $2,000 \mathrm{msec}$. With shorter durations, however, Weber fractions increased rapidly, as was pre- 
dicted by the generalized form of Weber's law. The outcome of Experiment 2 nicely replicates Getty's data for base durations ranging from 50 to $1,000 \mathrm{msec}$. Moreover, the present data complement Getty's findings by showing that the generalized Weber's law also holds for filled auditory intervals. It should be noted that the significant increase in Weber fractions was limited to the 50 -msec base durations with filled intervals, but that it also involved the $100-\mathrm{msec}$ base duration with empty intervals. This may be indicative of a more pronounced interfering effect of duration-independent sensory noise on the timing of empty rather than filled intervals. The present findings also appear to be consistent with Nakajima's (1987) model of empty duration perception in which DLs of empty intervals are expected to be in proportion to physical duration, plus a constant of about $80 \mathrm{msec}$.

We now turn our attention to four possible theoretical accounts of the discrimination profiles observed with filled and empty intervals in the present study. These theoretical accounts comprise the sensory-integration hypothesis (Rammsayer \& Lima, 1991), the internalmarker hypothesis (Grondin, 1993), the inverse latencyduration function hypothesis (Robin \& Royer, 1987), and the misassignment hypothesis (Kallman, Hirtle, \& Davidson, 1986). The absence of a statistically significant difference in Weber fractions between filled and empty auditory intervals for base durations ranging from 100 to $1,000 \mathrm{msec}$ and the virtually asymptotic curve progression (see Figure 1) are indicative of one unitary timing mechanism underlying temporal processing of both types of intervals irrespective of the base duration under investigation (cf. Grondin, 2001; Penney, 2003; Rammsayer \& Ulrich, 2001). Performance on duration discrimination is often interpreted by the assumption of a general neural counting mechanism. According to this class of models, a neural pacemaker generates pulses, and the number of pulses relating to a physical time interval is the subjective, internal representation of the duration of this interval. The higher the rate of pulses, the better the temporal resolution of this internal-clock mechanism (for reviews, see Grondin, 2001; Killeen \& Weiss, 1987; Rammsayer \& Ulrich, 2001).

Within the framework of internal clock models based on neural counting, several corollaries have been introduced to account for potential differences in the discriminability of filled and empty intervals. According to the sensoryintegration hypothesis (Rammsayer \& Lima, 1991), participants' responses in a duration-discrimination task may be facilitated by the availability of nontemporal cues such as the presence of a discernible physical stimulus during the interval. From this perspective, the physiological basis of better performance on filled than on empty intervals could be envisioned as an increase in neural firing rate due to the presence of a perceivable physical stimulus in the case of filled intervals (see, e.g., Evans, 1975). This higher firing rate should result in finer temporal resolution and thus less uncertainty about interval duration in filled than in empty intervals. Hence, the sensory-integration hypothesis would predict better temporal discrimination with filled than with empty intervals, irrespective of the base duration. Although this model could account for the higher temporal sensitivity of filled than of empty intervals at extremely brief base durations, it fails to predict the absence of a difference in performance on duration discrimination for base durations longer than $50 \mathrm{msec}$.

The internal-marker hypothesis proposed by Grondin (1993) was originally developed to explain better temporal discrimination for empty than for filled intervals. According to the internal-marker hypothesis, with filled intervals, the timing process is initiated with signal onset and is terminated when the internal trace of the signal wears off. With empty intervals, however, the timing process does not start until the internal trace of the onset marker has disappeared, and it ends as soon as the onset of the offset marker is detected. As a consequence, the internal representation of the duration of a filled interval should be longer than that of an empty interval of the same physical duration. Under these conditions, temporal discrimination should be better for empty than for filled intervals since, according to Weber's law, the difference between the standard and the comparison duration must increase with increasing standard duration (base duration) to achieve a comparable level of discrimination. This effect of internal onset-offset timing differences becomes increasingly negligible, and the discrimination advantage for empty intervals eventually should disappear for longer base durations. Thus, the internal-marker hypothesis would predict better discrimination of empty than of filled intervals at brief base durations, and no difference between both types of intervals at longer base durations. Although these predictions derived from the internalmarker hypothesis may be valid for perceived duration (cf. Grondin, 1993, 2003; Grondin et al., 1996), they do not appear to hold for duration discrimination of auditory intervals. Contrary to what would be expected on the basis of the internal-marker hypothesis, in the present study, better performance on duration discrimination was observed with filled than with empty intervals at the shortest base duration of $50 \mathrm{msec}$. This finding clearly argues against the validity of the internal-marker hypothesis - at least in the context of the present study.

A third explanation can be derived from the framework of Robin and Royer (1987), who studied auditory temporal processing by using a flutter-fusion paradigm, in which two tones were separated by a silent interval and participants were instructed to judge when the tone bursts fused perceptually by the adjustment of the duration of the first tone. Robin and Royer assumed a mutually inhibitory action between on cells, which begin to fire at stimulus onset, and off cells, which fire at stimulus offset, so that at the onset of a stimulus, the off response is inhibited. This inhibition decays, eventually allowing the off cell to fire; the latency with which this cell fires is governed by the "inverse latency-duration function," which states that the shorter the first stimulus, the longer the latency of the off cell. As a result, in empty intervals, a brief duration of the onset marker should cause a marked increase in the latency with which the off cell will fire. If we assume that this greater latency is accompanied by greater variability in registering marker offset, and if we further assume 
that off cells are likely to have a lower firing rate than on cells, it should be the case that empty intervals are processed much less accurately than filled intervals. The notion of an inhibitory interaction may represent a possible source of duration-independent variability in terms of the generalized Weber's law. The general validity of Robin and Royer's inverse latency-duration function hypothesis, however, is challenged by the fact that the discrimination of empty intervals has been shown to be largely independent of onset marker durations, at least for marker durations not exceeding $200 \mathrm{msec}$ (Rammsayer \& Leutner, 1996; Tse \& Penney, 2006).

Another theoretical account that could explain better performance with filled than with empty intervals is based on the misassignment hypothesis (Kallman, Beckstead, \& Cameron, 1988; Kallman et al., 1986). This theoretical approach proceeds from the notion that timing variability results from the misassignment of pulses generated by the internal pacemaker. According to the informationprocessing model of interval timing developed within the conceptual framework of scalar timing theory (Gibbon, 1977, 1991), the internal clock is composed of a pacemaker, a switch, and an accumulator (Church, 1984; Gibbon \& Church, 1984). The switch can be operated in different modes, some much more complex than others. It is plausible to assume that the simplest switch mode, in which the switch is on at the onset of a signal and off at the offset of a signal, is applied to filled-interval trials, whereas a more complex mode is applied to emptyinterval trials (cf. Rammsayer, 1994a; Rammsayer \& Lima, 1991). Unlike filled intervals, empty intervals require the processing of four events - that is, onsets and offsets of the auditory markers bounding the intervalwhereas no signal is present during the interval itself. If a more complex mode is more prone to error than the simplest mode, it should be the case that empty intervals are processed less accurately than filled intervals. In terms of the generalized Weber's law, the more complex switch mode associated with temporal processing of empty intervals could be perceived as a constant sensory noise. In accordance with the generalized form of Weber's law, this duration-independent source of additional variability in the timing process exerts a strong effect at extremely brief base durations. With increasing base duration, however, this effect is predicted to level off, as could be observed in Experiment 2.

A frequently expressed objection with regard to the use of brief, filled auditory intervals refers to the fact that stimulus energy is proportional to duration and that, especially for brief intervals, loudness is a strong function of duration. Therefore, discrimination between two auditory intervals in the range of milliseconds might be one of stimulus energy rather than of duration discrimination. Experimental data, however, indicate that duration discrimination of filled auditory intervals is based on an internal time code that is independent of stimulus energy. Several studies showed that changing stimulus intensity does not affect temporal discrimination of filled auditory intervals in the range of milliseconds (see, e.g., Abel, 1972b; Creelman, 1962; Henry, 1948; Small \& Campbell, 1962). In fact, the effect of stimulus energy on duration discrimination is negligible as long as the auditory stimulus is clearly detectable (Allan \& Kristofferson, 1974; Creelman, 1962). The most direct test of this proposition has been provided by Rammsayer (1994a). In his study, duration discrimination of filled intervals with a base duration of $50 \mathrm{msec}$ was assessed under three different conditions: (1) the standard and the comparison intervals were of equal loudness $(60 \mathrm{~dB}),(2)$ the standard interval $(85 \mathrm{~dB})$ was louder than the comparison intervals $(60 \mathrm{~dB})$, and (3) the comparison intervals $(85 \mathrm{~dB})$ were louder than the standard interval $(60 \mathrm{~dB})$. In all three conditions, the comparison intervals were always longer than the standard interval. If duration discrimination were based on differences in stimulus intensity - that is, intervals are judged to be longer simply because they sound louder-best performance should be expected for comparison intervals presented at a higher level of intensity than that of the standard interval, whereas poorest performance should be observed with the standard interval presented at a higher level of intensity than that of the comparison interval. The absence of any effect of energy values on duration discrimination performance in Rammsayer's (1994a) study clearly indicates that duration discrimination is based only on the temporal extent of the auditory intervals and not on some energy-dependent cues.

Finally, it should be noted that the present findings on performance on duration discrimination as an indicator of temporal sensitivity cannot be transferred directly to perceived duration as another aspect of temporal information processing. This is an important point, since a large number of studies on the effects of filled and empty intervals on temporal processing have used perceived duration as a dependent variable. Perceived duration appears to be based on processes that are at least partly different from those involved in temporal sensitivity. This assumption is supported by the following observations: (1) As was already described in the introduction, the perceived duration of empty intervals is much more susceptible to changes of the duration of the first marker bounding the interval than to performance on duration discrimination. (2) Differences in perceived duration of filled and empty intervals can be observed at durations considerably longer than $100 \mathrm{msec}$ (see, e.g., Droit-Volet, 2008; Wearden, Norton, Martin, \& Montford-Bebb, 2007), whereas in the present study, we failed to reveal a difference in temporal sensitivity as a function of type of interval for base durations longer than $100 \mathrm{msec}$. (3) Experimentally induced changes in directed attention differentially affect measures of perceived duration and temporal sensitivity (Mattes \& Ulrich, 1998).

To sum up, in the present study, we substantiated superior performance on duration discrimination with filled as compared with empty auditory intervals in the range of tens of milliseconds, whereas no performance differences could be shown for base durations ranging from 100 to $1,000 \mathrm{msec}$. Furthermore, the present findings are consistent with the notion of a unitary timing mechanism that 
governs the timing of both filled and empty auditory intervals, independent of base durations. A likely conceptual framework that can account for our data represents a psychophysical model based on the misassignment hypothesis or the assumption of a switch component as proposed by the information-processing model of interval timing. Future research is required to investigate to what extent the present findings can be generalized to other psychophysical procedures as well as to other sensory modalities.

\section{AUTHOR NOTE}

The author thanks Simon Grondin, Yoshitaka Nakajima, and two anonymous reviewers for helpful comments and suggestions. Correspondence concerning this article should be addressed to T. H. Rammsayer, Department of Psychology, University of Bern, Muesmattstrasse 45, CH-3000 Bern 9, Switzerland (e-mail: thomas.rammsayer@psy.unibe.ch).

\section{REFERENCES}

Abel, S. M. (1972a). Discrimination of temporal gaps. Journal of the Acoustical Society of America, 52, 519-524.

ABEL, S. M. (1972b). Duration discrimination of noise and tone bursts. Journal of the Acoustical Society of America, 51, 1219-1223.

Allan, L. G. (1979). The perception of time. Perception \& Psychophysics, 26, 340-354.

Allan, L. G., \& Kristofferson, A. B. (1974). Psychophysical theories of duration discrimination. Perception \& Psychophysics, 16, 26-34.

Church, R. M. (1984). Properties of the internal clock. In J. Gibbons \& L. G. Allan (Eds.), Timing and time perception (Annals of the New York Academy of Sciences, Vol. 423, pp. 566-582). New York: New York Academy of Sciences.

Creelman, C. D. (1962). Human discrimination of auditory duration. Journal of the Acoustical Society of America, 34, 582-593.

Droit-Volet, S. (2008). A further investigation of the filled-duration illusion with a comparison between children and adults. Journal of Experimental Psychology: Animal Behavior Processes, 34, 400-414.

Evans, E. F. (1975). Cochlear nerve and cochlear nucleus. In W. D. Keidel \& W. D. Neff (Eds.), Handbook of sensory physiology: Vol. 5, Pt. 2 (pp. 1-108). Berlin: Springer.

FitzGibions, P. J., \& Gordon-Salant, S. (1994). Age effects on measures of auditory duration discrimination. Journal of Speech \& Hearing Research, 37, 662-670.

Fraisse, P. (1978). Time and rhythm perception. In E. Carterette \& M. Friedman (Eds.), Handbook of perception (Vol. 8, pp. 203-254). New York: Academic Press.

GetTY, D. J. (1975). Discrimination of short temporal intervals: A comparison of two models. Perception \& Psychophysics, 18, 1-8.

GibBon, J. (1977). Scalar expectancy and Weber's law in animal timing. Psychological Review, 84, 279-325.

GibBON, J. (1991). Ubiquity of scalar timing with a Poisson clock. Journal of Mathematical Psychology, 35, 1-11.

Gibbon, J., \& Church, R. M. (1984). Sources of variance in an information processing theory of timing. In H. L. Roitblat, T. G. Bever, \& H. S. Terrace (Eds.), Animal cognition (pp. 465-488). Hillsdale, NJ: Erlbaum.

Grondin, S. (1993). Duration discrimination of empty and filled intervals marked by auditory and visual signals. Perception \& Psychophysics, 54, 383-394.

Grondin, S. (2001). From physical time to the first and second moments of psychological time. Psychological Bulletin, 127, 22-44.

Grondin, S. (2003). Sensory modalities and temporal processing. In $\mathrm{H}$. Helfrich (Ed.), Time and mind II: Information processing perspectives (pp. 61-77). Cambridge, MA: Hogrefe \& Huber.

Grondin, S. (2008). Methods for studying psychological time. In S. Grondin (Ed.), Psychology of time (pp. 51-74). Bingley, U.K.: Emerald.

Grondin, S., Ivry, R. B., Franz, E., Perreault, L., \& Metthé, L. (1996). Markers' influence on the duration discrimination of intermodal intervals. Perception \& Psychophysics, 58, 424-433.
Grondin, S., Meilleur-Wells, G., Ouellette, C., \& Macar, F. (1998). Sensory effects on judgments of short time intervals. Psychological Research, 61, 261-268.

HENRY, F. M. (1948). Discrimination of the duration of a sound. Journal of Experimental Psychology, 38, 734-743.

Kaernbach, C. (1991). Simple adaptive testing with the weighted updown method. Perception \& Psychophysics, 49, 227-229.

Kallman, H. J., Beckstead, J. W., \& Cameron, P. A. (1988). Ipsilateral and contralateral masking of duration. Perception \& Psychophysics, 43, 31-37.

Kallman, H. J., Hirtle, S. C., \& Davidson, D. (1986). Recognition masking of auditory duration. Perception \& Psychophysics, 40, 45-52.

Karmarkar, U. R., \& Buonomano, D. V. (2003). Temporal specificity of perceptual learning in an auditory discrimination task. Learning \& Memory, 10, 141-147.

Killeen, P. R., \& Weiss, N. A. (1987). Optimal timing and the Weber function. Psychological Review, 94, 455-468.

KIRK, R. E. (1995). Experimental design: Procedures for the behavioral sciences. Pacific Grove, CA: Brooks/Cole.

Kraemer, P. J., Randall, C. K., \& Brown, R. W. (1997). The influence of stimulus attributes on duration matching-to-sample in pigeons. Animal Learning \& Behavior, 25, 148-157.

Lapid, E., Ulrich, R., \& Rammsayer, T. (2008). On estimating the difference limen in duration discrimination tasks: A comparison of the $2 \mathrm{AFC}$ and the reminder task. Perception \& Psychophysics, 70 , 291-305.

Lapid, E., Ulrich, R., \& Rammsayer, T. (2009a). Comparison of two variants of the method of constant stimuli for estimating difference thresholds. Swiss Journal of Psychology, 68, 189-192.

Lapid, E., Ulrich, R., \& Rammsayer, T. (2009b). Perceptual learning in auditory temporal discrimination: No evidence for a cross-modal transfer to the visual modality. Psychonomic Bulletin \& Review, 16, 382-389.

LevitT, H. (1971). Transformed up-down methods in psychoacoustics. Journal of the Acoustical Society of America, 49, 467-477.

Luce, R. D., \& Galanter, E. (1963). Discrimination. In R. D. Luce, R. R. Bush, \& E. Galanter (Eds.), Handbook of mathematical psychology (Vol. 1, pp. 191-243). New York: Wiley.

MacInNIS, M. L. M. (2007). Do rats time filled and empty intervals of equal duration differently? Behavioural Processes, 75, 182-187.

MatTes, S., \& UlRICH, R. (1998). Directed attention prolongs the perceived duration of a brief stimulus. Perception \& Psychophysics, 60, 1305-1317.

Miki, A., \& SAnTI, A. (2005). The perception of empty and filled time intervals by pigeons. Quarterly Journal of Experimental Psychology, 58B, 31-45.

Nakajima, Y. (1987). A model of empty duration perception. Perception, 16, 485-520.

Penney, T. B. (2003). Modality differences in interval timing: Attention, clock speed, and memory. In W. H. Meck (Ed.), Functional and neural mechanisms of interval timing (pp. 209-233). Boca Raton, FL: CRC Press.

Pfeuty, M., Ragot, R., \& Pouthas, V. (2008). Brain activity during interval timing depends on sensory structure. Brain Research, 1204, $112-117$.

RAMMSAYER, T. H. (1994a). Effects of practice and signal energy on duration discrimination of brief auditory intervals. Perception \& Psychophysics, 55, 454-464.

RAMMSAYER, T. H. (1994b). Temporal information processing in blind and sighted subjects. In L. M. Ward (Ed.), Fechner Day '94. Proceedings of the Tenth Annual Meeting of the International Society for Psychophysics (pp. 179-184). Vancouver: International Society for Psychophysics.

Rammsayer, T. [H.], \& Altenmüller, E. (2006). Temporal information processing in musicians and nonmusicians. Music Perception, 24, $37-48$.

RAMmsayer, T. H., \& BRANDLER, S. (2004). Aspects of temporal information processing: A dimensional analysis. Psychological Research, 69, $115-123$.

Rammsayer, T. H., \& Grondin, S. (2000). Psychophysics of human timing. In R. Miller (Ed.), Time and the brain (pp. 157-167). Reading, U.K.: Harwood Academic Publishers. 
Rammsayer, T. H., \& Leutner, D. (1996). Temporal discrimination as a function of marker duration. Perception \& Psychophysics, 58, 1213-1223.

Rammsayer, T. H., \& Lima, S. D. (1991). Duration discrimination of filled and empty auditory intervals: Cognitive and perceptual factors. Perception \& Psychophysics, 50, 565-574.

Rammsayer, T. H., \& SKrandiES, W. (1998). Stimulus characteristics and temporal information processing: Psychophysical and electrophysiological data. Journal of Psychophysiology, 12, 1-12.

RAmmsayer, T. [H.], \& Ulrich, R. (2001). Counting models of temporal discrimination. Psychonomic Bulletin \& Review, 8, 270-277.

Robin, D. A., \& Royer, F. L. (1987). Auditory temporal processing: Two-tone flutter fusion and a model of temporal integration. Journal of the Acoustical Society of America, 82, 1207-1211.

Santi, A., Keough, D., Gagne, S., \& van Rooyen, P. (2007). Differential effects of empty and filled intervals on duration estimation by pigeons: Tests of an attention-sharing explanation. Behavioural Processes, 74, 176-186.

Santi, A., Miki, A., Hornyak, S., \& Eidse, J. (2006). The perception of empty and filled time intervals by rats. Behavioural Processes, 71, 144-156.
Small, A. M., \& Campbell, R. A. (1962). Temporal differential sensitivity for auditory stimuli. American Journal of Psychology, 75, 401-410.

Stoтt, L. H. (1933). The discrimination of short tonal durations. Unpublished doctoral dissertation, University of Illinois at Urbana.

Tse, C.-Y., \& Penney, T. B. (2006). Preattentive timing of empty intervals is from marker offset to onset. Psychophysiology, 43, 172-179.

Wearden, J. H., Norton, R., Martin, S., \& Montford-Bebb, O. (2007). Internal clock processes and the filled-duration illusion. Journal of Experimental Psychology: Human Perception \& Performance, 33, 716-729.

Woodrow, H. (1928). Behavior with respect to short temporal stimulus forms. Journal of Experimental Psychology, 11, 167-198.

Woodrow, H. (1930). The reproduction of temporal intervals. Journal of Experimental Psychology, 13, 473-499.

Woodrow, H. (1951). Time perception. In S. S. Stevens (Ed.), Handbook of experimental psychology (pp. 1224-1234). New York: Wiley.

(Manuscript received January 5, 2010; revision accepted for publication April 1, 2010.) 